\title{
Linking System Quality, Information Quality and Intention of Use to Student Satisfaction of Student Information System in China
}

\author{
Samar Zaineldeen', Li Hongbo', Masud Ibrahim² and Sohail Ibrahim ${ }^{3}$ \\ ${ }^{1}$ School of Management, Jiangsu University,xuefu Rd,JinKou,Zhenjiang,Jiangsu, China \\ ${ }^{2}$ School of Finance \& Economics, Jiangsu University, xuefu Rd,JinKou,Zhenjiang,Jiangsu,China \\ ${ }^{3}$ School of Computer Science and Communication Engineering, Jiangsu University, Xuefu Rd, \\ JinKou, Zhenjiang, Jiangsu, China
}

\begin{abstract}
The substantial growth in China's education field has given a considerable boost to competition between many administrations within the sector. This study's primary motive is assessing international student satisfaction concerning the information systems in large numbers of universities situated in Jiangsu province, China. A self-structured questionnaire was used for data collection and analyzed through descriptive and inferential statistics. The study was analyzed based on user satisfaction within the system, information quality, and intention to use. This research analysis was to inspect the consequence of students' perceived ease of use, perceived usefulness, and intention to use the student information system. A sample of 400 respondents was chosen based on a proportional stratified sampling approach across the universities' various faculties. PLS- (SEM) approach was embraced for the investigation of data using PLS graph software. The major finding was that information quality and system quality has a considerable and critical effect on user satisfaction. Moreover, the intention of use has a considerable negative effect on student satisfaction.
\end{abstract}

KEY WORDS: STUDENT SATISFACTION, STUDENT INFORMATION SYSTEM, INFORMATION AND SYSTEM QUALITY, THE INTENTION OF USE.

\section{INTRODUCTION}

Technology has brought many changes in our everyday life, and education is one of the fields where the impact can be noticed. With digital technologies and the Internet growing rapidly, new learning methods were created. The progress in technology had reached a stage where new terms and concepts were introduced in the education field . Education is an important area for improving and promoting the standards and learning qualities; the Internet is used with great success. For students interested in studying in top universities abroad, Chine is always in the top 3 choices as it is the largest education hub of Asia and the third-largest education hub globally, with about

Biosc Biotech Res Comm P-ISSN: 0974-6455 E-ISSN: 2321-4007

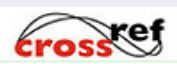

Identifiers and Pagination

Year: 2021 Vol: 14 No (5) Special Issue

Pages: $324-332$

This is an open access article under Creative

Commons License Attribn 4.0 Intl (CC-BY).

DOI: $h$ ttp://dx.doi.org/10.21786/bbrc/14.5/56
492,000 overseas students, according to the ministry of education. Situated in China, Jiangsu province is one of China's biggest regions concerning the number of universities and overseas students. Throughout the vital tasks, i.e., enrollment, housing, evaluation, registration, mark delivery, the offering of classes, and class schedules, the Student facilitation or information system helps handle student-related information. This study aims to assess overseas students' fulfilment concerning the information systems in large numbers of universities located in Jiangsu universities.

In the management information system's discipline, contentment with IS (Information system) has been the main core of extensive research. It is mostly used as a substitute measure for IS success. With the work of, user satisfaction research got noticed, and it stayed in continuity through and work. As a structure and methodology for evaluating the powerful-dependent factor in IS (which stands for Information System) study, DeLone and McLean introduced in 1992 the performance methodology of the information systems ('D\&M IS performance model, Switzerland / Germany, 1992) as

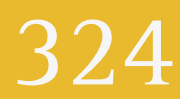


a system. Almost 300 papers were referenced and used the Information System Performance Model in refereed journals from to. The Revised D\&M Information System Performance Model was then introduced for DeLone \& t McLean in 2003 and evaluated these papers. For a qualitative approach of the Jiangsu province for a large number of the international students' satisfaction, a sample of 400 overseas learners was elected through a proportional stratified sampling technique.

The study was performed based on a self-structured list of questions and evaluated through inferential and descriptive. Use had to be positioned behind consumer fulfilment during the process sense; thus, constructively involvement with usage will trigger further projecting satisfaction level casually. A higher objective to use is continuously motivated by greater user contentment. The most commonly employed single-measure metric may be customer satisfaction. The student information system (SIS) provides postgraduate and undergraduate learners facilities, such as operative admission procedures, enrollment, reimbursement of university fees, appeal for housing, confirmation of assessment status, and relevant information about the university. Nevertheless, of this system's useful benefits towards overseas students, its effectiveness would still depend on the students' fulfilment. SIS efficiency can be assessed effectively only through feedback from consumers. Users can verify their expectations and determine their strength in the system's progress through the feedback as an indication and weighbridge. The vital criticize can only be made effectively through an investigation to determine (SIS) operators' unguarded views. The study will conclude which (IS) measurement pointers are perceived the most in consumers' satisfaction. The outcome would allow consumers to handle assets based on the satisfaction directories experiential initially.

1.1 Research Objectives: Study for the factors that affect the student information system's use by international students studies in many universities located in Jiangsu province, China. The study was analyzed based on user satisfaction within the information and system quality and its intention to use. The purpose of this research analysis was to inspect the consequence of students' perceived usefulness, and perceived ease of use, intention to use the student information system.

\section{Literature}

2.1 System Quality: Considered as the processing characteristic of IS, the term also referred to as the measurement of the data handling framework itself. Delone and Mclean have distinguished: reliability, usefulness, responsiveness, usability, and adaptability as the foremost system quality components in a considerable number of studies performed in recent decades concerning the usage and execution of internet business. In the year 2000, Lin and $\mathrm{Lu}$ conducted that IS quality comprises the quality of information, reaction time, and access to the system. That, among which time, is the point of reference component of perceived usefulness. Negash, Ryan et al. affirmed that the framework structure adopted the entire framework feature, which is significant for client fulfilment. He has verified that availability and accessibility are key components of system quality factors in designing a web-based client supporting framework. These two variables are the most dominant markers as far as client fulfilment. Our method for deciding system consistency in how an IS will procedure an incident. The evaluation parameters incorporate stability, the simplicity of utilizing the system, the extent of user-friendliness, convenience, and instantaneity.

2.2 Information quality: Information quality was indicated in the idea of sort, level of detail, and the assortment of information chosen during the framework and advancement stages. Additionally, allude to the report's substance, which is viewed as a productivity estimation of the client's data quality. The information content includes understandability, accuracy, sufficiency, and relevance, while the configuration manner of presentation, timeliness, and information result. There is solid support in the writing to attach client fulfilment with the information's quality. The nature of data positively affects the usefulness of a website and perceived ease of use. Information quality alludes to having this distinctiveness: various, inclusive, comprehensive, correct, appropriate, applicable, and dependable. The same study found that information quality; system quality had a noteworthy effect on usefulness and ease of use. The standard of the data provided by the system is our model for defining information quality. The assessment criteria include dependability, accuracy, and correctness.

2.3 Perceived Ease of Use: PEOU stands for Perceived Ease of Use. As per Davis et al., how much an individual accepts that a specific program is liberated from physical and mental exertion is seen as easy to utilize. Unique utilization of PU and PEOU is affected by clients. It is found that the PEOU has huge ramifications for the satisfaction of the IS. For example, various research discoveries, for example, the reason for utilizing the E-govt stage, Twitter, and others, have affirmed the beneficial outcome of PEOU on specialized maintainability. In this examination, PEOU refers to how much understudies feel that it will be simple, reasonable, and adaptable to utilize the student information system.

2.4 Perceived Usefulness: PU stands for Perceived Usefulness. It has been built up utility to improve the program's proficiency, which would likewise positively affect the client's inspiration to utilize the system]. Grudin considers that usefulness is the issue of whether the system be able to use to get some desired target Perceived usefulness works satisfactorily in terms of client fulfilment. Seddon and Kiew declared that perceived usefulness is prognostic of client fulfilment, and Rai et al. watched that the ERP program's apparent adequacy has an affirmative relationship.PU in this study utility identifies with the level to which understudies feel it is significant for understudies to get the data required through an understudy data framework that makes their life simple, and the program is helpful by and large. 
2.5 Intention-to-use: For the reason that there's complexity in translating the multidimensional components of "use," DeLone \& McLean contend that "intention to use" will be an advisable substitute measure in some contexts. "Intention to use" is an approach, although "use" is a manner. Intention-to-use is the client's conclusive choice to acknowledge or reject the service; the contributions were explained. The goal to utilize was one of the key factors utilized for assessing the utilization of a data framework or data innovation in most TAM-based models. The last component that shows the endorsement of innovation or technique.

2.6 User satisfaction: Agreeing with Doll and Torkzadeh, client fulfilment is "the affective approach towards a particular PC program". Seddon portrays the client fulfilment as "an emotional appraisal on a lovely and horrendous continuum of different outcomes (individual, hierarchical, the social effect of IS use)." User fulfilment is a helpful instrument for assessing the effect of IS and web/web benefits just as a key component in utilizing innovations. DeLone and McLean declared that client fulfilment among the system impacts intention to use, and this will be extraordinarily expanded if the accomplishment of individuals, affiliations, or associations is upgraded after the system is used. They additionally distinguished client fulfilment as the manner variable and revealed that client fulfilment is connected equally to intention to use and use Our model's assessment and fulfilment levels The criteria for evaluation embrace fulfilment with the interface, information, and general system performance.

\section{MATERIAL AND METHODS}

A detailed survey design was applied to examine the IS users' satisfaction indices amongst the international students (postgraduate and undergraduate) for a large number of Jiangsu province Universities in China. The sample of the respondents for this research includes overseas students from all faculties in the universities. This sample of 400 learners were chosen based on the proportional stratified sampling scheme across the universities' variety faculties. A self-structured feedback form regarding ISs was designed to collect the data. The survey was conducted directly (face to face) with the students, retrieving the questionnaires after distributing the questionnaire for analyzing it.

PLS-SEM approach was embraced for the investigation of data using PLS graph software. The IS scholarly network utilizes this product as a standard. The normal examination factor is determined as a framework by this product. As it were, the relationship of all elements to each other is determined. The PLS diagram likewise does the checking of the confirmative components. This procedure has been viewed as useful by numerous organizations and craftsmanship ventures, and the achievement in instruction is expanding through this type of arrangement.
3.1 Research Design: The study's survey was performed utilizing 5 point Likert's Scale as the survey designed. It debates the assembly of statistics from the consumers (international undergrad and postgrad learners) of their universities' IS. Their feedback is estimated to provide comprehension of evaluating the information system's user contentment level.

3.2 Research framework: Figure (1) shows the forming of this examination procedure. Speculations for causal connections have been found in the bolt that connected latent variables. This model ordinarily had six factors (constructs), with four dependent variables and two independent variables.

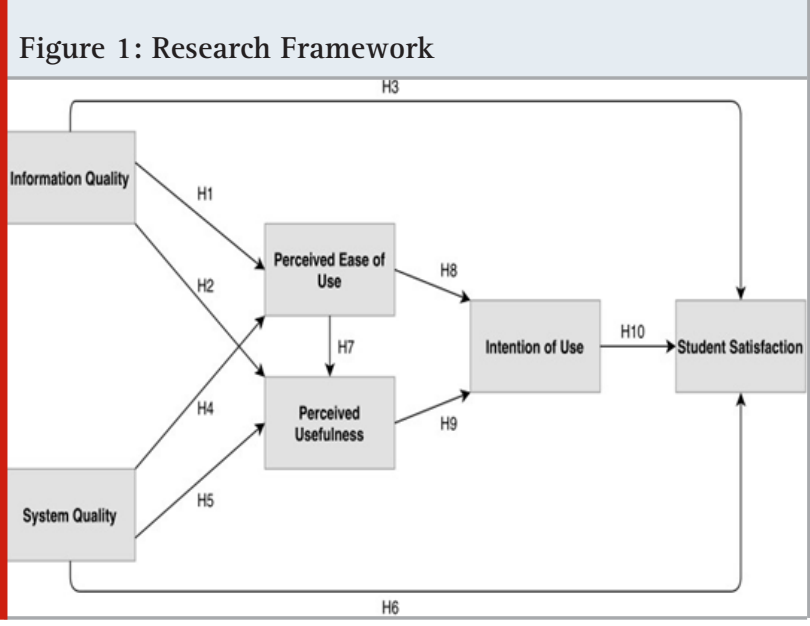

Table 1. The features of the respondents according to demographic

\begin{tabular}{|l|c|c|c|}
\hline \multirow{2}{*}{ Variable } & Dimension & Occurrence & Percent \\
\hline \multirow{2}{*}{ Gender } & Male & 188 & 47.0 \\
\cline { 2 - 4 } & Female & 212 & 53.0 \\
\hline \multirow{2}{*}{ Age } & $17-23$ & 202 & 50.0 \\
\cline { 2 - 4 } & $24-30$ & 64 & 16.0 \\
\cline { 2 - 4 } & $31-44$ & 133 & 33.3 \\
\cline { 2 - 4 } & Other & 1 & 0.3 \\
\hline \multirow{3}{*}{ Program } & Bachelor & 179 & 44.8 \\
\cline { 2 - 4 } & Master & 147 & 36.8 \\
\cline { 2 - 4 } & PhD & 74 & 18.4 \\
\hline
\end{tabular}

Table 2. KMO and Bartlett's Test

\begin{tabular}{|l|c|c|}
\hline ITEMS & KMO & Bartlett's Test of Sphericity \\
\hline IQ & .745 & 1741.907 \\
\hline SQ & .903 & 3011.471 \\
\hline PEOU & .609 & 521.018 \\
\hline PU & .653 & 1072.287 \\
\hline IU & .688 & 636.494 \\
\hline SS & .740 & 1446.310 \\
\hline
\end{tabular}


3.3 Hypotheses: The following theories are suggested in the present study, and these theories are based on historical literature and its context.

H1: Information quality has a considerable and affirmative impact on perceived ease of use.

H2: Information quality has a considerable and affirmative impact on perceived usefulness.

H3: Information quality has a considerable and affirmative impact on student satisfaction. H4: System quality has a considerable and affirmative impact on perceived ease of use.

H5: System quality has a considerable and affirmative impact on perceived usefulness. H6: System quality has a considerable and affirmative impact on student satisfaction.

H7: Perceived ease of use has a considerable and affirmative impact on perceived usefulness.

H8: Perceived ease of use has a considerable and affirmative impact on the intention of use.

H9: Perceived usefulness has a considerable and affirmative impact on the intention of use.

H10: Intention of use has a considerable and affirmative impact on student satisfaction.

3.4 Processing and Analysis of Data: SPSS18.0 is the coding and documenting of substantial polls. When the information got is given in frequency and rate, PLS-SEMs are regularly utilized for speculation creation in scientific science. After investigating the consider variables and their latent constructs on user fulfilment was implied in brilliant PLS Version 3.2.7 PLS-SEM is picked as the most popular sociology innovation, the most appropriate multivariate testing strategy.

\section{RESULTS}

4.1 Characteristics of Respondents Based on Demographics: Table (1) be evidence for the features of the students based on the demography. Almost all respondents were female, with 53\%, and 47\% were males. Age-wise, those aged 17- 23 contributed with the highest ratio of 50\%, followed by age 24-30 16\%. Those between $31-34$ and other age were $33.3 \%$ and $0.3 \%$, respectively $44.8 \%$ of respondents were bachelor student while $36.8 \%$ and $18.4 \%$ were masters and $\mathrm{PhD}$ scholars.

4.2 Confirmatory Factor Analysis (CFA): CFA is utilized to look at the origin and impact relationship among measurement variables and latent variables to affirm if such connection is steady through the observed data [39;40]. We tested for the standard method variation in our research; thus, the factor test was implemented, and EFA was applied for the test.
4.3 Reliability and Validity of Scales: EFA was employed through SPSS to measure the underlying factors associated. Bartlett's Test of Sphericity was utilized to measure the theory validity while the Kaiser-MeyerOlkin (KMO) was applied to evaluate individual variables' sampling sufficiency. It is considering that the general of the KMO should be 0.6 or further for the variable analytical. The above outcomes exposed that both are substantial, and it is reasonable for the factor to analyze (See Table 1). The cumulative variation in the table demonstrations $74.50 \%$ for information quality, 90.30\% for system quality, 60.90\% for perceived ease of use, $65.30 \%$ for perceived usefulness, and $68.80 \%, 74 \%$ for the intention of use and student satisfaction respectively, which surpasses the minimum approval level of $60 \%$. The table once more designates that Bartlett's Test of Sphericity is adequate for its correlation. These values constitute proof that there is convergent and discriminate validity (Table 3).

Discriminant validity explained with the determination of each construct's certain variable is different match up to the rest of the constructs. The value for its crossloading in the latent variable is above the rest of the constructs. Table (3) above illustrations the discriminant investigation concerning the scales used in this research. A higher factor than some other structure in its scale is required for Discriminant analysis. All the scales in table (3) demonstrate the constructs loading superior to any other factor on their scales. Information quality on its scale had a value of about (0.95), and the intention to use had a value roughly (0.97) over some other structure on its scale. PEOU and PU had a value of (0.84) and (0.90) correspondingly, (0.96) for student satisfaction.

\subsection{Measurement and structure equation modelling analysis}

4.4.1 Verifications Validity of Convergent: Convergence validity identifies with test results' coherence as various techniques are utilized to determine the equivalent aspect. This paper utilized SmartPLS measurable program for confirmatory factor analysis. Table (4) demonstrates that latent variables of the model's standardized factor loading were within $0.672-0.986$, all-surpassing 0.5. All the variables in table (4) describe that the Cronbach's Alpha is over 0.70, indicating that all the table constructs have sophisticated reliability within the context of measurement. Fornell \&t Larcker clarified in their research that constructs validity measures how a measurement symbolizes and realistically associates the detected incident to the construct through the essential hypothesis.

In contrast, evaluation is made through discriminant validity and convergent validity. From Table (4), the estimation of Rho. Rho was calculated to appraise the reliability of the latent variables. As revealed in table (4), the estimate of Rho for each of the factors used substantially more than the concurred estimation of 0.5 . The Average Variance Extracted (AVEs) is considered the essential measure for examining the convergent validity. Table (4) highlights the AVE values used as 
a measure for checking the validity. Minimum (AVE) requirement for convergent validity is 0.5 . and the composite reliability (CR) has a minimum of 0.5 and
0.70 , correspondingly confirmations that the convergent validity is satisfactory.

\begin{tabular}{|c|c|c|c|c|c|c|}
\hline FACTOR & ITEMS & LOADING & CRONBACH'S ALPHA & rho-A & CR & AVE \\
\hline \multirow[t]{3}{*}{ INFORMATION QUALITY } & IQ1 & .968 & .974 & 975 & .983 & .951 \\
\hline & IQ2 & .986 & & & & \\
\hline & IQ3 & .971 & & & & \\
\hline \multirow[t]{5}{*}{ SYSTEM QUALITY } & SQ1 & .954 & .975 & .984 & .980 & .907 \\
\hline & SQ2 & .962 & & & & \\
\hline & SQ3 & .966 & & & & \\
\hline & SQ4 & .957 & & & & \\
\hline & SQ5 & .931 & & & & \\
\hline \multirow[t]{3}{*}{ PERCEIVED EASE OF USE } & PEOU1 & .672 & .808 & 893 & .884 & .721 \\
\hline & PEOU2 & .939 & & & & \\
\hline & PEOU3 & .911 & & & & \\
\hline \multirow[t]{3}{*}{ PERCEIVED USEFULNESS } & PU1 & .783 & .888 & .928 & .932 & .821 \\
\hline & PU2 & 965 & & & & \\
\hline & PU3 & .958 & & & & \\
\hline \multirow[t]{3}{*}{ INTENTION OF USE } & IU1 & .883 & .869 & .884 & .919 & .791 \\
\hline & IU2 & .932 & & & & \\
\hline & IU3 & .852 & & & & \\
\hline \multirow[t]{3}{*}{ STUDENT SATISFACTION } & SS1 & .951 & .962 & 965 & .974 & .929 \\
\hline & SS2 & .961 & & & & \\
\hline & SS3 & .979 & & & & \\
\hline
\end{tabular}

Figure 2: Graphic symbolize Cronbach's Alpha

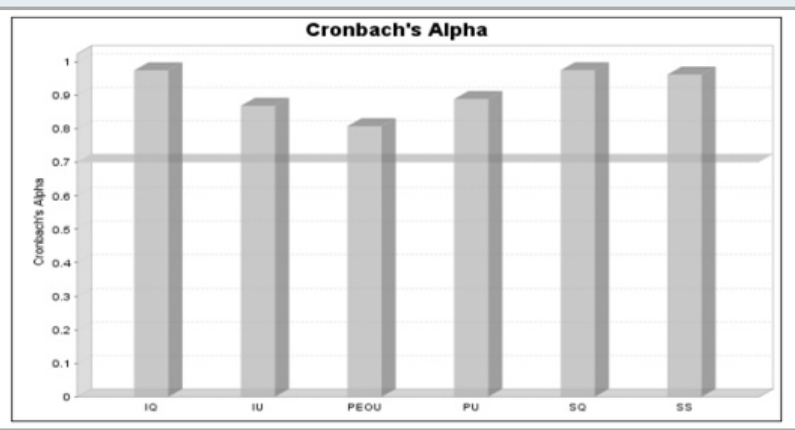

Figure 3: Graphic symbolize CR

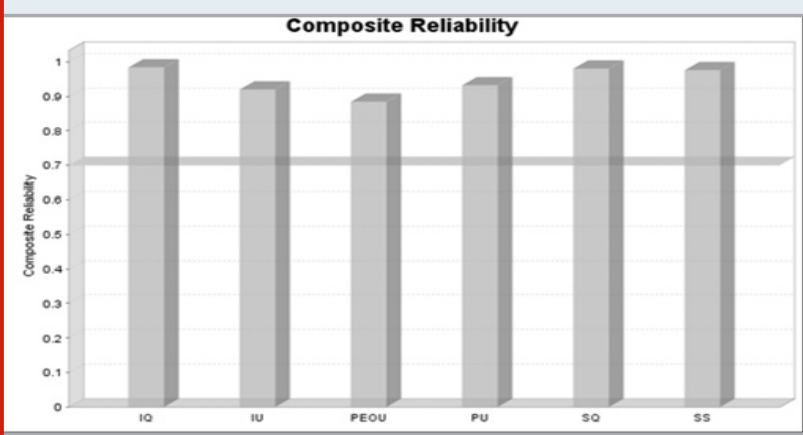

"The Fornell \& Larcker model, besides cross-loadings, have been applied to measure discriminant legitimacy. The suggested standard is that a build ought not to reveal
Figure 4: Graphical representation Average Variance Extracted (AVE)

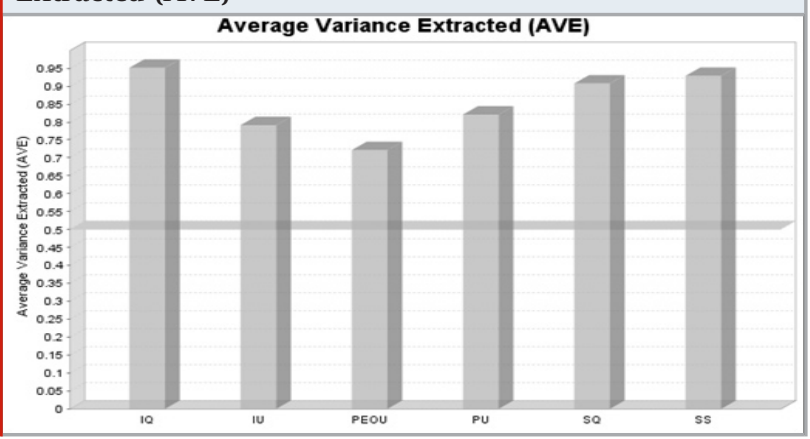

Figure 5: Graphic symbolize rho_A

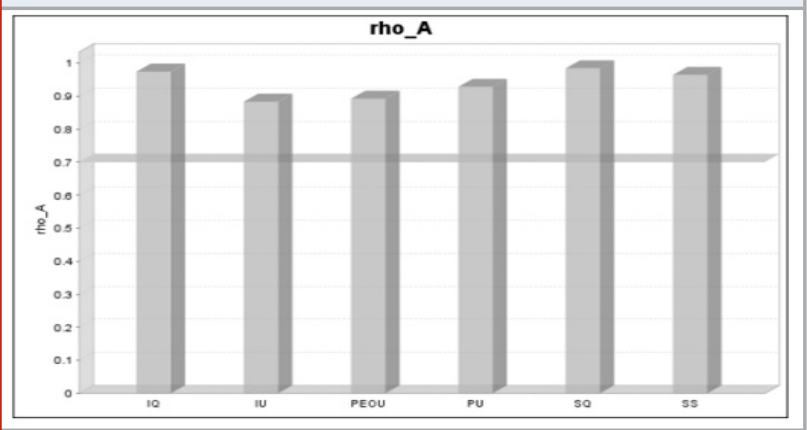

an equal variance as whatever other expansion that is further than its AVE esteem. Table (5) explains the Fornell 
\& Larcker standard trial of the paradigm in which the squared connections were distinguished and the other dormant associations developed. Table (5) determines that most of the links were small compared to the squared basis of the expected difference applied along the diagonals, proposing key discriminant legitimacy. This confurmation that each build's experimental variables demonstrated the given inert factor confurms the model's deviating accuracy. However, table(6) specifies that every watched variable's cross-loading was further than the between inter-connections of the construct of the numerous observed factors in the model. In this way, these findings stated the cross-loadings assessment ideologies and provided reasonable consent to the estimation model's discriminant validity. As this closes, the given model was predictable to be measured to satisfactorily unwavering reliability, discriminant validity, convergent validity, besides the study model's assessment.

Table 5. Checking Discriminant validity using FornellLarcker "s measure

\begin{tabular}{|l|c|c|c|c|c|c|}
\hline & IQ & IU & PEOU & PU & SQ & SS \\
\hline IQ & 0.975 & & & & & \\
\hline IU & -0.034 & 0.890 & & & & \\
\hline PEOU & -0.015 & 0.791 & 0.849 & & & \\
\hline PU & 0.963 & -0.041 & 0.066 & 0.906 & & \\
\hline SQ & 0.571 & 0.027 & 0.039 & 0.544 & 0.952 & \\
\hline SS & 0.974 & -0.054 & -0.046 & 0.939 & 0.536 & 0.964 \\
\hline
\end{tabular}

Table 6. Cross Loadings

\begin{tabular}{|l|c|c|c|c|c|c|}
\hline & IQ & IU & PEOU & PU & SQ & SS \\
\hline IQ1 & 0.968 & -0.032 & -0.022 & 0.930 & 0.528 & 0.966 \\
\hline IQ2 & 0.986 & -0.037 & -0.033 & 0.959 & 0.563 & 0.961 \\
\hline IQ3 & 0.971 & -0.030 & 0.012 & 0.929 & 0.580 & 0.922 \\
\hline IU1 & -0.106 & 0.883 & 0.757 & -0.113 & 0.023 & -0.125 \\
\hline IU2 & 0.012 & 0.932 & 0.740 & 0.010 & 0.048 & -0.014 \\
\hline IU3 & 0.016 & 0.852 & 0.594 & 0.005 & -0.002 & 0.010 \\
\hline PE0U1 & 0.060 & 0.387 & 0.672 & 0.128 & -0.016 & 0.048 \\
\hline PE0U2 & -0.083 & 0.750 & 0.939 & -0.014 & 0.041 & -0.110 \\
\hline PE0U3 & 0.017 & 0.785 & 0.911 & 0.091 & 0.053 & -0.016 \\
\hline PU1 & 0.645 & -0.060 & 0.278 & 0.783 & 0.354 & 0.631 \\
\hline PU2 & 0.952 & -0.030 & -0.003 & 0.965 & 0.540 & 0.927 \\
\hline PU3 & 0.975 & -0.031 & -0.028 & 0.958 & 0.557 & 0.949 \\
\hline SQ1 & 0.478 & 0.082 & 0.066 & 0.450 & 0.945 & 0.449 \\
\hline SQ2 & 0.537 & 0.010 & 0.035 & 0.519 & 0.962 & 0.501 \\
\hline SQ3 & 0.501 & 0.060 & 0.067 & 0.479 & 0.966 & 0.467 \\
\hline SQ4 & 0.511 & 0.094 & 0.091 & 0.484 & 0.957 & 0.485 \\
\hline SQ5 & 0.653 & -0.082 & -0.048 & 0.623 & 0.931 & 0.616 \\
\hline SS1 & 0.881 & -0.078 & -0.048 & 0.847 & 0.464 & 0.951 \\
\hline SS2 & 0.986 & -0.037 & -0.033 & 0.959 & 0.563 & 0.961 \\
\hline SS3 & 0.943 & -0.045 & -0.052 & 0.902 & 0.519 & 0.979 \\
\hline
\end{tabular}

4.4.2 Hypothesis Test: Commonalities were initiate in the path coefficients within the PLS and the standard b- coefficient in the regression investigation. The relevance of the theories was confirmed through the b-value. Estimation of dissimilarity in the subordinate construct intended for a unit variant in the autonomous construct(s) was designated by the value of b. For the theorized model, the b-value was computed for each path. The greater the b-value, the greater the large impact was distinguished on the endogenous latent construct. Yet, the importance level of the b-value had to be experienced by the T-statistics test. An assessment was done through the procedure to specify the hypothesis's significance. A bootstrapping implementation was performed for the study using 1000 sub-samples with no noteworthy changes to measure the path coefficient's implication and the T- statistics values. It is labelled in table (7).

Seven of ten hypotheses were accepted; this means H2, H3, H6, H7, H8, H9, and $\mathrm{H} 10$ had significant influence. Some of the hypotheses as H1, H4, and H5 were not accepted. In $\mathrm{H} 1$, we predicted that the quality of information has no critical impact on perceived ease of use. The outcomes in Table 7. and Figure (6) confirmed that the quality of information has $(b=-0.055$, $\mathrm{T}=0.778$, and $\mathrm{p}=0.437$ ); therefore, $\mathrm{H} 1$ is worthless. The information quality substantially affects perceived usefulness $(b=0.972, T=85.176$, and $p$.

$<0.000$ ), so $\mathrm{H} 2$ is valid. the impact of information quality on student fulfillment was affirmative and important $(b=0.989, T=144.893$ and $p<0.000)$ presents that $\mathrm{H} 3$ was sustained, $\mathrm{H} 4$ is invalid with $(b=0.071, \mathrm{~T}=0.879$ and $\mathrm{p}=0.379$ ) give us evidence that system quality has no critical impact on perceived ease of use. the system quality has no considerable influence on perceived usefulness it is invalid ( $b=-0.014, T=1.098$ and $p=0.272$ ), the result show that $\mathrm{H} 6$ system quality has a noteworthy effect on student satisfaction with $(b=-0.028, T=2.497$, $\mathrm{P}=0.013), \mathrm{H} 7$ is valid and perceived ease of use has a considerable influence on perceived usefulness $(b=0.081$, $\mathrm{T}=3.592, \mathrm{p}<0.000$ ). for $\mathrm{H} 8$ perceived ease of use has a considerable impact on the intention of use with (b $=0.797, \mathrm{~T}=20.013$ and $\mathrm{p}<0.000$ ) so H8 is valid .H9 and $\mathrm{H} 10$ are valid the result show that perceived usefulness has a significant influence on intention of use also the intention of use has a significant impact on student satisfaction with $(b=-0.094, T=3.160$ and $p=0.002)$, $(b=-0.028, T=1.837$ and $p=0.066)$. In case if the beta coefficient is considerable, inspect the sign of the beta. If the beta coefficient is positive, the explanation is for every one unit increment in the indicator variable; the product variable will increment by the beta value. Sometimes, the beta has a negative sign; the explanation is that the product variable will diminish by the beta value for every one-unit increase in the indicator variable. The result shows that H6, H9, and H10 had a significant negative relationship.

4.4.3 Correlation Coefficient of Latent Variables: Table (8) deliberates the latent variable correlation coefficient. Table (8) discloses that a significant correlation happens between two constructs; the latent endogenous and the latent exogenous. 


\begin{tabular}{|c|c|c|c|c|c|}
\hline \multicolumn{2}{|c|}{ Hypothesis path } & \multirow{2}{*}{$\begin{array}{c}\text { Standardize beta } \\
-0.055\end{array}$} & \multirow{2}{*}{\begin{tabular}{|c|} 
T Statistics \\
0.778 \\
\end{tabular}} & \multirow{2}{*}{$\begin{array}{c}\text { P Values } \\
0.437\end{array}$} & \multirow{2}{*}{$\begin{array}{c}\text { Action } \\
\text { Not Acceptec }\end{array}$} \\
\hline $\mathrm{H} 1$ & IQ -> PEOU & & & & \\
\hline $\mathrm{H} 2$ & IQ -> PU & 0.972 & 85.176 & 0.000 & Accepted \\
\hline H3 & IQ -> SS & 0.989 & 144.893 & 0.000 & Accepted \\
\hline $\mathrm{H} 4$ & SQ -> PEOU & 0.071 & 0.879 & 0.379 & Not Accepted \\
\hline H5 & SQ -> PU & -0.014 & 1.098 & 0.272 & Not Accepted \\
\hline H6 & SQ $->$ SS & -0.028 & 2.497 & 0.013 & Accepted \\
\hline $\mathrm{H} 7$ & PEOU -> PU & 0.081 & 3.592 & 0.000 & Accepted \\
\hline H8 & PEOU -> IU & 0.797 & 20.013 & 0.000 & Accepted \\
\hline H9 & PU -> IU & -0.094 & 3.160 & 0.002 & Accepted \\
\hline H10 & IU $->$ SS & -0.028 & 1.837 & 0.046 & Accepted \\
\hline
\end{tabular}

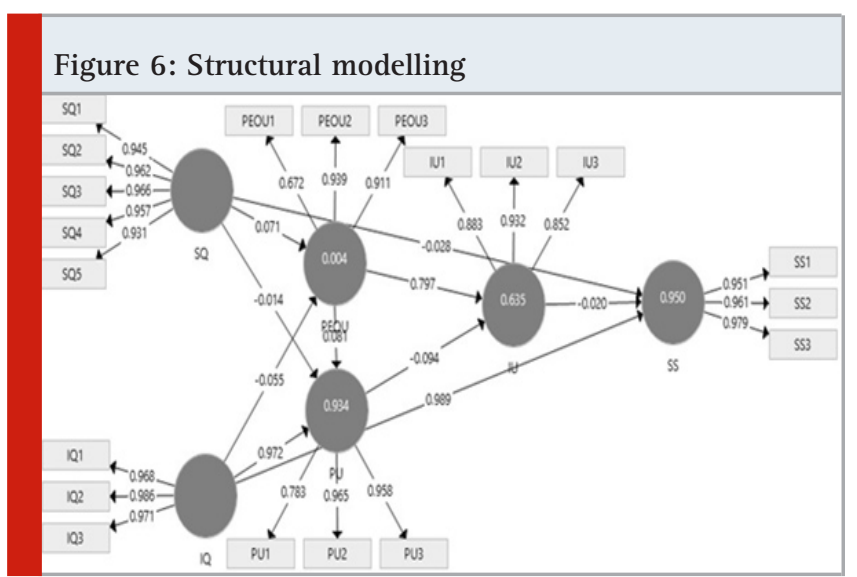

Table 8. Correlations of Latent Variable

\begin{tabular}{|l|c|c|c|c|c|c|}
\hline & IQ & IU & PEOU & PU & SQ & SS \\
\hline IQ & 1.000 & -0.034 & -0.015 & 0.963 & 0.571 & 0.974 \\
\hline IU & -0.034 & 1.000 & 0.791 & -0.041 & 0.027 & -0.054 \\
\hline PEOU & -0.015 & 0.791 & 1.000 & 0.066 & 0.039 & -0.046 \\
\hline PU & 0.963 & -0.041 & 0.066 & 1.000 & 0.544 & 0.939 \\
\hline SQ & 0.571 & 0.027 & 0.039 & 0.544 & 1.000 & 0.536 \\
\hline SS & 0.974 & -0.054 & -0.046 & 0.939 & 0.536 & 1.000 \\
\hline
\end{tabular}

\section{DISCUSSION}

The main target of the examination is to analyze the variables impact using the student information system by international students study in a large number of universities located in Jiangsu province, China. The study was analyzed based on user satisfaction within the IQ, $\mathrm{SQ}$, and IU. The study aimed to investigate the influence of students' PEOU, PU, and intention of using the student information system. Moreover, this study assessed SIS and how the learners understand its applications in completing their system demands. The finding displays the sustaining importance of the information on user contentment. The IQ and SQ of IS impact customers' repeat of usage and satisfaction. Moreover, (Lin et al. point out that information system quality knows how to foresee users' (PU) successfully and (PEOU). Therefore, we hypothesize (H1) and (H4). For (H1), this study come across that IQ has no critical affirmative impact on PEOU. As a result, the abundant and constant information offer has no noteworthy affirmative impact on the student information system's ease of use.

According to Seddon, Information System is an accomplishment and a very effective model so; this relationship has been reinforced, where they substituted 'IS use' of DeLone and McLean's accomplishment model by PU. Seddon affirms that PU is impacted straightforwardly by beliefs regarding IQ. A short time later, Rai et al. analyzed and endorsed Seddon's and its changed models and figured out the impact of IQ on PU to be sure as well as gigantic. In this manner have also argued that increased information quality leads to improved usefulness; this way, we hypothesize (H2) IQ has a considerable effect on PU. The SEM outcomes confirm that the quality of information was determined as the 2 nd biggest impacting factor within factors influencing perceived usefulness.

Several prior examinations on Information System accomplishment have displayed support for the conflict that more elevated levels of information quality brief improved customer satisfaction. Hence, we hypothesize (H3) IQ has a considerable and critical impact on user satisfaction; the outcomes illustrate that the quality of information attribute had the major coefficient within the path context, i.e., $b=0.989$ with thorough influencing learner satisfaction. For (H4), this study finds that SQ has no considerable affirmative effect on PU, with $(b=$ $0.071, p$-value $=0.379$ ). The solid connection between found system quality and perceived usefulness was found by Floropoulos et al. (2010). On the other hand, the impact of SQ on PU was found insignificant. The test considered was founded on Internet education and consequently couldn't be a key factor to distinguish perceived usefulness. We subsequently assume that (H5) System quality has a considerable and important effect on perceived usefulness; the study finds that the system quality doesn't have any noteworthy affirmative effect on PEOU with $(b=-0.014$, $p$-value $=0.272)$. 
The earlier experimental conclusion has encouraged the affirmative and noteworthy effect of system quality on client fulfilment as tended in DeLone and McLean's model. In any case, Floropoulos et al. found it insignificant. Consequently, we hypothesize (H6) SQ has an affirmative and noteworthy effect on user satisfaction, the consider finds that SQ has a significant negative effect on user satisfaction, as we mentioned that in case the beta coefficient is a negative sign, the explanation that for every one-unit increase in the indicator variable, the product variable will reduce through the beta coefficient value. Several studies supported the positive association of PEOU with PU Hence we hypothesize (H7) PEOU has a positive and significant influence on PU; the result shows $\mathrm{H7}$ is valid, and PEOU has a significant influence on PU.

For (H8), we found that PEOU has a considerable impact on IU; the result shows perceived ease of use has a significant effect on IU. The meta-investigation figures out there's a clear impact of PU on IU as considerable. This relationship didn't analyze in the IS success model in education sector research as per our information. Taking into consideration the general performance of the relationship in IS study in and specifically, in embracing research, the subsequent hypothesis can be prepared (H9) PU has a considerable and noteworthy impact on IU, the result shows that PU has a negative and significant effect on IU, as well for (h10) the intention of use has a considerable negative effect on student satisfaction.

\section{CONCLUSION}

The study was analyzed based on user satisfaction within the information, system quality, and intention to use. The study aimed to investigate the influence of students' perceived ease of use, perceived usefulness, and intention of using the student information system. The survey was carried out directly with the international students' study in a large number of universities located in Jiangsu province, China. Retrieve of the questionnaires after the distribution; the data was found suitable for examining. A structural equation modelling (SEM) approach was utilized to investigate data using PLS graph software. For the theorized framework, the b-value was determined for each path. Yet, the implication level of the b-value had to be verified with the T-statistics test. An evaluation was made to identify the relevance of the theories. Seven of ten hypotheses were accepted. Some of the hypotheses as H1, H4, and H5 were not accepted. Moreover, we discussed that Sometimes the beta has a negative sign; the explanation is that the result variable will diminish by the beta value for every one-unit increase in the indicator variable. The result shows that H6, H9, and H10 had a significant negative relationship with user satisfaction.

\section{REFERENCES}

Ahn, T., et al. (2007). "The impact of Web quality and playfulness on user acceptance of online retailing." 44(3): 263-275.

Ajzen, I. and M. J. P. B. Fishbein (1975). ”A Bayesian analysis of attribution processes." 82(2): 261-277.

Ajzen, I. J. O. B. and H. D. Processes (1991). "The theory of planned behavior."50(2): 179-211.

Alkhanak, S. a. A. K. and I. A. G. J. N. E. R. Azmi (2011). "University students information technology experience and its role towards e-learning orientation." 24(2): 231242.

Bagozzi, R. P. and Y. J. J. o. t. a. o. m. s. Yi (1988). ”On the evaluation of structural equation models." 16(1): 74-94.

Bailey, J. E. and S. W. J. M. s. Pearson (1983). "Development of a tool for measuring and analyzing computer user satisfaction." 29(5): 530-545.

Baleghi-Zadeh, S., et al. (2014). "Learning Management System Utilization among Malaysian Higher Education Students: A Confirmatory Factor Analysis.” 3(1): 369386.

Bamgbade, J. A., et al. (2017). "Malaysian construction firms' social sustainability via organizational innovativeness and government support: The mediating role of market culture." 154: 114-124.

Bhattacherjee, A. J. M. Q. "Understanding Information Systems Continuance: An Expectation-Confirmation Model." 25(3): 351-370.

Chin, W. W. (1998). Commentary: Issues and opinion on structural equation modeling, JSTOR

Chin, W. W., et al. (1998). "The Partial Least Squares Approach to Structural Equation Modeling." 8(2). Chismar, W. G. and S. J. P. A. A. S. A. S. Wiley-Patton (2002). "Test of the technology acceptance model for the Internet in pediatrics." 155-159.

Davis, F. (1989). "Perceived Usefulness, Perceived Ease of Use, and User Acceptance of Information Technology." MIS Quarterly

Delone, W. H. and E. R. J. I. J. o. e. c. Mclean (2004). "Measuring e-commerce success: Applying the DeLone \&t McLean information systems success model." 9(1): 31-47.

DeLone, W. H. and E. R. J. I. s. r. McLean (1992). "Information systems success: The quest for the dependent variable." 3(1): 60-95.

Delone, W. H. and E. R. J. J. o. m. i. s. McLean (2003). "The DeLone and McLean model of information systems success: a ten-year update." 19(4): 9-30.

Doll, W. J. and G. J. M. q. Torkzadeh (1988). "The measurement of end-user computing satisfaction." 259-274.

Ferrari, A., et al. (2012). Understanding digital competence in the 21st century: An analysis of current frameworks. European Conference on Technology Enhanced Learning.

Floropoulos, J., et al. (2010). "Measuring the success of the Greek taxation information system." 30(1): 4756.

Fornell, C. and D. F. J. J. o. M. R. Larcker "Evaluating Structural Equation Models with Unobservable Variables and Measurement Error.” 18(1): 39-50. 
Franz, C. R. and D. J. D. s. Robey (1986). ”Organizational context, user involvement, and the usefulness of information systems.” 17(3): 329-356

Gelderman, M. J. I. and management (1998). "The relation between user satisfaction, usage of information systems and performance." 34(1): 11-18.

Grudin, J. J. I. w. c. (1992). "Utility and usability: research issues and development contexts." 4(2): 209217.

Hair Jr, J. F., Sarstedt, M., Hopkins, L., \&t Kuppelwieser, V. G. (2014). Partial least squares structural equation modeling (PLS-SEM). European business review.

Hsu, M.-H., et al. (2004). "Predicting electronic service continuance with a decomposed theory of planned behaviour." 23(5): 359-373

Igbaria, M., et al. (1990). "Correlates of user satisfaction with end user computing: an exploratory study." 19(2): 73-82.

Ives, B., et al. (1983). "The measurement of user information satisfaction."

Lin, C. C. and H. L. J. I. J. o. I. Management "Towards an understanding of the behavioural intention to use a web site." 20(3): 0-208.

Liu, C., et al. (2000). "Exploring the factors associated with Web site success in the context of electronic commerce." 38(1): 23-33.

Liu, V. and M. J. J. o. t. a. f. i. s. Khalifa (2003). "Determinants of satisfaction at different adoption stages of Internet-based services." 4(1): 12.

Mathieson, K. J. I. s. r. (1991). "Predicting user intentions: comparing the technology acceptance model with the theory of planned behavior." 2(3): 173- 191.

McGill, T., et al. (2003). "User developed applications and information systems success: A test of DeLone and McLean's model." 16(1): 24-45.

Messick, S. J. E. r. (1994). "The interplay of evidence and consequences in the validation of performance assessments." 23(2): 13-23.

Molla, A., et al. "eCommerce adoption in developing countries: a model and instrument." 42(6): 877-899.

Montazemi, A. R. and H. Q. Saremi (2013). Factors Affecting Internet Banking Pre-Usage Expectation Formation. Hawaii International Conference on Systems Sciences (HICSS 2013).

Negash, S., et al. (2003). "Quality and effectiveness in web-based customer support systems.” 40(8): 757768.

Özdamar, 囚., et al. (2017). "Petrology of the shoshonitic Çamba $\bigotimes_{1}$ pluton in NE Turkey and implications for the closure of the Neo-Tethys Ocean: Insights from geochemistry, geochronology and $\mathrm{Sr}-\mathrm{Nd}$ isotopes." 284: 477-492.

Pinsonneault, A. and K. J. J. o. m. i. s. Kraemer (1993). "Survey research methodology in management information systems: an assessment." 10(2): 75-105.

Rai, A., et al. "Assessing the Validity of IS Success Models: An Empirical Test and Theoretical Analysis." 13(1): 50-69.

Redecker, C. and 0. J. E. J. o. E. Johannessen (2013). "Changing Assessment - Towards a New Assessment Paradigm Using ICT." 48(1): 79-96.

Ringle, C. M., et al. (2015). "SmartPLS 3. Bönningstedt: SmartPLS.” 15: 2016

Sarstedt, M., et al. (2014). "Partial least squares structural equation modeling (PLS-SEM): A useful tool for family business researchers." 5(1): 105-115.

Seddon, P. and M.-Y. Kiew (1994). "Partial Test And Development ot Delone and McLean's Model of Information Success."

Seddon, P. B. J. I. S. R. ”A Respecification and Extension of the DeLone and McLean Model of IS Success." 8(3): 240-253.

Sibona, C. and S. Walczak (2012). Purposive sampling on Twitter: A case study. 2012 45th Hawaii International Conference on System Sciences, IEEE

Song, H., Cai, H., Brown, J. D., \&t Grimm, K. J. . (2011). Differential item functioning of the Rosenberg self-esteem scale in the US and China: Measurement bias matters. Asian Journal of Social Psychology.

Srinivasan, A. J. M. Q. (1985). "Alternative Measures of System Effectiveness: Associations and Implications." 9(3): 243-253.

Wang, Y.-S. and Y.-W. J. G. i. q. Liao (2008). ”Assessing eGovernment systems success: A validation of the DeLone and McLean model of information systems success.” 25(4): 717-733.

Wangpipatwong, T. (2008). The Extended Constructivist E-learning Environment Model.

Wu, J. H., et al. (2006). "Measuring KMS success: A respecification of the DeLone and McLean's model." 43(6): 728-739. 